\title{
Fluxo de Notificação de Queda no Sistema de Informação Hospitalar
}

\author{
Silvia Helena Frota Mendonça ${ }^{1}$ \\ Juliana Silveira Rodrigues Gonçalo² \\ Carolina Augusto Bezerra ${ }^{3}$
}

\section{Introdução}

A literatura lista algumas barreiras principais para subnotificações de eventos adversos, tais como falta de tempo, risco de punição, sobrecarga de trabalho e também o modelo de notificação.

O fluxo de notificação e análise de queda era burocrático (ficha impressa), segmentado e havia perda de tempo entre as áreas com retrabalho nas análises, duplicidade de notificações, além de risco de extravios e subnotificações.

O tempo médio entre a ocorrência de queda e o recebimento no Gerenciamento de Risco era de 14 dias.

\section{Objetivo}

Descrever as etapas para implantação da Ficha de Notificação Eletrônica de Queda, para reduzir o tempo entre a ocorrência do evento e a análise por parte do Gerenciamento de Risco (GR).

Reduzir o número de subnotificações de queda, independente do dano.

\section{Método}
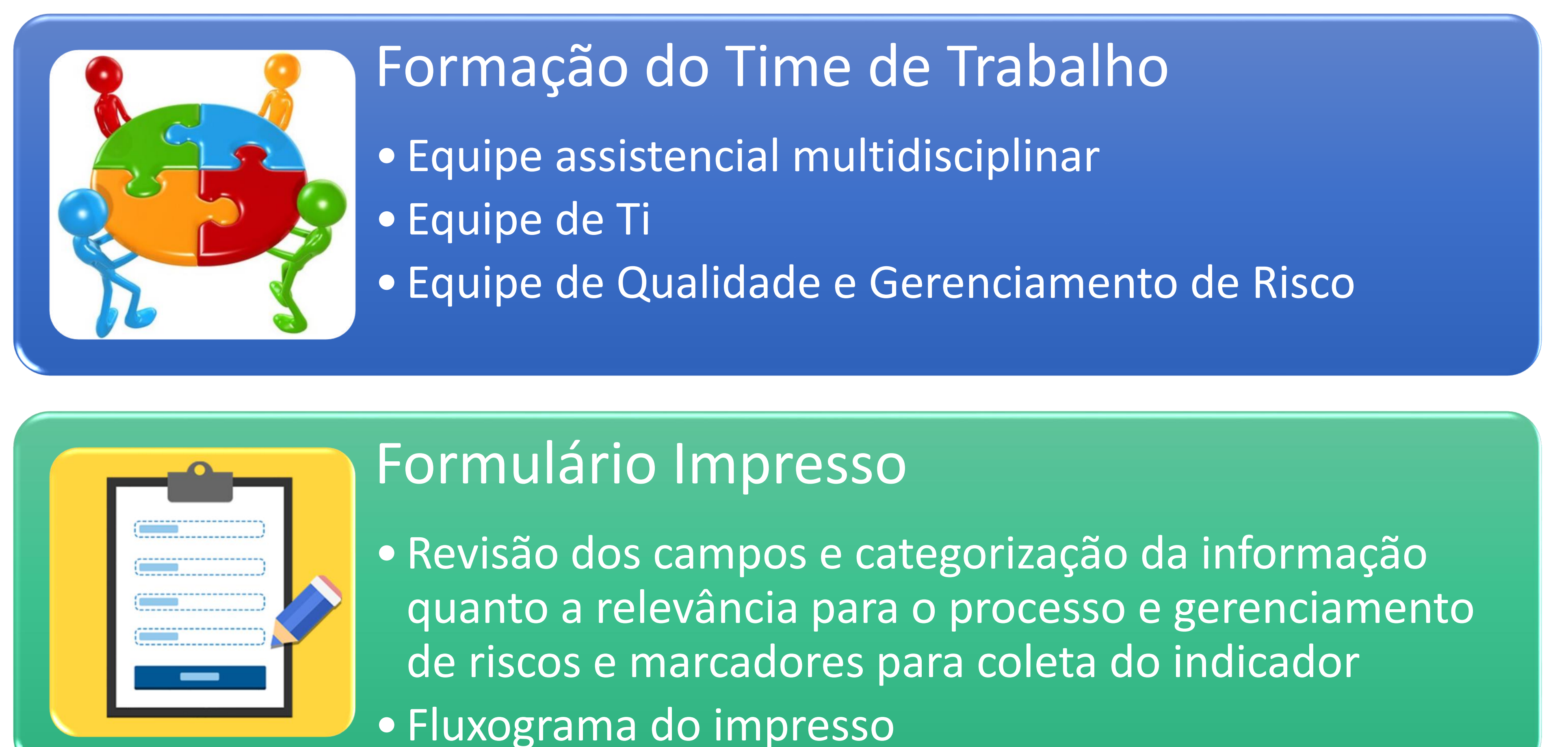

Formulário Impresso

- Revisão dos campos e categorização da informação quanto a relevância para o processo e gerenciamento de riscos e marcadores para coleta do indicador - Fluxograma do impresso

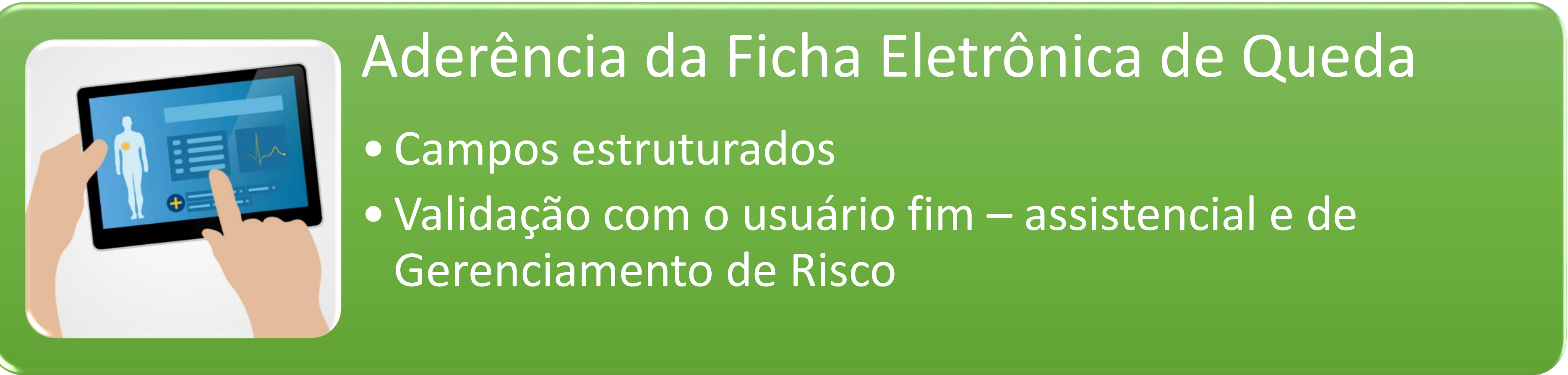

\section{Resultados}

Com a implantação do sistema de informação hospitalar foi criado um time multidisciplinar para explorar as possibilidades da ferramenta para implantação de melhorias no fluxo de notificação e análise de queda.

O time fez análise crítica dos campos do impresso com o objetivo de categorizar as informações de acordo com o grau de relevância, considerando o histórico de informações gerenciadas pela gestão do protocolo, informações importantes para o gerenciamento de riscos e marcadores para coleta dos indicadores. Por fim, foi comparado as informações consideradas como relevantes e as constantes na Ficha eletrônica de Queda e feito validação pelo usuário assistencial.

No novo fluxo de notificações de quedas foram excluídas 5 etapas, diminuindo o tempo do processo e o risco de subnotificação ou extravio. A ficha eletrônica para notificação de queda é composta de 11 campos, incluídos dados estatísticos e fatores contribuintes, eliminando tempo na etapa de tabulação dos dados.

Após estruturação da ferramenta eletrônica, foi realizada validação pelo usuário de gerenciamento de risco e as estratégias de comunicação da alteração do fluxo foram: divulgação em fóruns gerenciais, aplicação de Lição de um Ponto - LUP para equipe multidisciplinar e Comunicado Interno Institucional via e-mail.

\section{Conclusão}

A revisão do fluxo de notificação de Queda proporcionou eliminar etapas sem valor agregado, retrabalhos e, principalmente, agilidade no acesso aos dados.

A qualidade da informação gerada foi de grande importância para equipe assistencial, gestão do protocolo e gerenciamento de risco, garantindo maior confiabilidade nas informações e maior eficiência nas análises de ações de melhorias para promover a segurança dos pacientes. 